\title{
Flipped Science Fair: Engaging Middle-School Students in STEM while Training Researchers in Science Communication
}

\author{
Lorena Benedetti $1^{1,}$ and Richard B. Crouse ${ }^{2}$ \\ ${ }^{1}$ Department of Neuroscience and Cell Biology and ${ }^{2}$ Interdepartmental Neuroscience Program Yale University School of Medicine, New Haven, CT \\ "Current Affiliation: HHMI Janelia Research Campus, Ashburn, VA \\ Keywords: Public Engagement, Science Outreach, Science Fair, Communication, Middle School Students, STEM \\ Publication Date: September 30, 2020
}

DOI: https://doi.org/10.15695/jstem/v3i1.10

\begin{abstract}
The Flipped Science Fair (FSF) transforms the traditional science fair format by having middle-school students judge the research of early career scientists. At the FSF, students learn about cutting-edge research in a small group setting, with opportunities to ask questions and participate in hands-on demonstrations. By placing the students in the role of the "judge," the event gives students the opportunity to engage with scientists interactively and with authority. The FSF also provides science communication training for the presenting scientists. Leading up to the event, the presenters attend three workshops focused on distilling their research message to a middle-school level. The FSF effectively promoted science engagement by middle school students who expressed increased interest in science after the event. Moreover, presenters reported an improvement in their science communication skills to a broad audience and increased confidence during public speaking. Our partnership with Pathways to Science, Yale's coordinated STEM outreach infrastructure, enables us to measure the FSF's effectiveness long term, since the Pathways program tracks student trajectories through their college education. The success of the FSF led to the organization of satellite and virtual events, which provided more opportunities for public engagement and gave presenters additional chances to share their research.
\end{abstract}

\section{INTRODUCTION}

The ultimate goal of outreach programs in science, technology, engineering, and mathematics (STEM) is to efficiently and effectively communicate science to the public (Ufnar et al., 2012). Science communication to the general public has been acknowledged as a responsibility of scientists (Bass, 2016; Leshner, 2003). Scientific concepts can be complicated, and communicating these concepts often requires the use of discipline-specific jargon and terminology. However, scientists should be able to convey the relevance of their work with accessible language in order to help the lay audience understand the importance of scientific research and to make scientifically supported decisions that influence politics, allocation of resources or their individual health (Bass, 2016; Leshner, 2003). Science communication to the general public is a skill that requires a lot of practice and careful attention to language, tone, and diction. Unfortunately, few undergraduate and graduate science curricula offer opportunities to practice these skills, and most scientists do not receive formal training in science communication (Bernard and Michaut,
2013; Brownell et al., 2013; Moni et al., 2007; Oliveira et al., 2019; Petzold and Dunbar, 2018). Science outreach events represent a unique opportunity for students to receive informal training in science communication to the public.

There are several challenges in the effective organization of science outreach events, such as the recruitment of scientists, mathematicians, physicists, and engineers willing to dedicate some of their time to collaborating with educators and community leaders in order to increase students' interest and excitement around science (Alberts, 1994; Colwell, 1998; Ufnar et al., 2012), as well as the allocation of funds to support these programs. The educational value of science outreach programs assessed by several studies has shown significant positive impacts of these programs, both on the communication, teaching, time-management and team-work skills of the scientists involved as educators, and on the academic performance of students participating in the program (Gamse et al., 2010; Thompson et al., 2002; Ufnar et al., 2012). 
Another important role of STEM outreach programs is to motivate women and underrepresented minorities to pursue scientific careers. It has been reported that women and underrepresented students are less likely to undertake a science or engineering major at the start of their college experience, and less likely to complete STEM majors should they enroll (Fouad and Santana, 2017; Landivar, 2013). It is well established, however, that educational programming in STEM, along with mentorship from senior colleagues who share similar gender or ethnic backgrounds, are more successful in motivating and encouraging underrepresented students to tackle and complete STEM majors in college at roughly the same rate as their non-minority peers (Johnson and Okoro, 2016).

Identified as one of the most "typical demographic" areas in the United States (Kolko, 2016), New Haven, Connecticut, is a fertile ground for the development of science outreach programs that appeal to a wide audience. While New Haven possesses a population diverse in ethnic, racial, educational, and socioeconomic backgrounds (Kolko, 2016) it is also one of the cities with the fastest growing income inequality in the country (Holmes and Berube, 2014). In areas with limited prosperity, municipalities face challenges raising the necessary revenue to provide essential public services, and ultimately prevents local schools from providing low-income students with an adequate education (Holmes and Berube, 2014).

In an attempt to address how these issues may impact representation in science, organizations affiliated with Yale University offer a wide range of science outreach events with these populations in mind. One such organization is Yale Pathways to Science, which identifies local middle and high school students who show promise in STEM fields and provides them access to numerous and diverse STEM programs, workshops, and classes. Of the over 1,600 Pathways students, 53\% are from groups traditionally underrepresented in STEM majors and careers, $49 \%$ would be the first in their family to attend college, and 56\% are female (unpublished data from Pathways to Science). Taking a different, yet complementary, approach to addressing local disparities in STEM education and engagement, the graduate student and post-doctoral researcher organization Yale Science Diplomats (YSD) blends science communication training and professional development with public outreach. An example initiative is the annual Science in the News lecture series, where researchers give talks on trending topics in science at a public library, effectively and engagingly communicating the implications and importance of their science. This type of intentional science outreach development is a critical first step to truly reach out to New Haven's diverse population.

The past successes of events like Science in the News and the intent to continue engaging New Haven's residents motivated YSD to partner with Pathways to Science to or- ganize the Flipped Science Fair, a science outreach event where middle-school students learn about cutting edge science from Yale students and postdoctoral researchers (Benedetti and Crouse, 2019). The Flipped Science Fair embodies the missions of both organizations. It gives middle-school students the opportunity to interact with real scientists, who explain their research using simplified versions of scientific conference posters and hands-on demonstrations. Additionally, the event trains scientists in effective science communication, specifically with a non-expert audience (Friedman, 2008).

The Flipped Science Fair shares features of other successful programs such as "Kids Judge!," a science fair where researchers explain their work to fourth-grade student judges (Mervis, 2010), and the "Reverse Science Fair," where graduate students present their work in local high schools (Mernoff et al., 2017). Other outreach programs involve high school students who carry out research projects under the supervision of an undergraduate or graduate student mentor (DeClue et al., 2000; Fink, 2009; Lacalle and Petruso, 2012). The Flipped Science Fair does not entail the development of a research project from the student participants. Instead graduate students present their research in a poster format to provide middle school students with the opportunity to discuss science in an informal setting. Presenters are specifically trained to guide middle schoolers through the formulation of a research question, the design of experiments whose results will facilitate answering that question, and the analysis and interpretation of the data collected. In our event, the researchers are young adults from diverse cultural backgrounds, allowing the middle school students to easily relate to them and become motivated to pursue a scientific career.

One of the goals of the Flipped Science Fair is to create a science outreach event targeting middle-school students in order to reach students early enough in their education to choose electives and extracurriculars that best prepare them for science majors. Additionally, another important objective is to formally train scientists who volunteer to present a poster at the event in science communication. This is achieved thanks to the organization of three workshops: the Research Story, the Graphic Design, and the Dry Run. These workshops teach presenters how to effectively explain their research to a general audience and how to graphically represent the content of their science in an intuitive manner. The effectiveness of the Flipped Science Fair in the promotion of science engagement was revealed by the student and presenter feedback after the event. The majority of the students not only enjoyed being a judge during the fair, but they also reported increased interest in science. Presenters also reported positive outcomes: an improvement in their science communication skills to a lay audience and more confidence with public speaking. 


\section{METHODS}

Advertising and Informational Session. To expose middle school students to a broad range of scientific research, researchers were recruited from science and social science departments at Yale University. Departments involved included neuroscience, cell biology, chemistry, physics, biomedical engineering, psychology, and others. In an attempt to obtain a diverse group of presenters, a variety of recruitment techniques were used, including sending emails to all science and social science departments at Yale, posting advertisements for the event on social media, and hanging posters about the event in various locations around campus. Interested individuals were invited to an informational session where they were asked to present a five-minute summary of their research using a single slide with visuals. Members of the Flipped Science Fair organizing committee assessed the individuals on their enthusiasm, clarity, and ability to answer questions about their research. Individuals who participated to the informational session and demonstrated a desire to develop their science communication skills were invited to participate in the event.

Science Communications Workshops. In the months before the event, the selected presenters participated in three workshops to learn strategies for effective science communication (Figure 1A). The first workshop, the Research Story Workshop, emphasized oral communication skills. The second workshop, the Graphic Design Workshop, focused on how to use images, drawings, and schematics to visually represent data. The third workshop, the Dry Run, combined the skills learned during the previous two workshops, with participants being asked to give a twelve-minute presentation of their research project in language accessible to middle school students, while using a complete version of their poster as visual aid. Before every workshop, the presenters were provided with materials to help them prepare for the planned activities. During each workshop, the presenters received feedback from peers and members of the Flipped Science Fair organizing team.

The Research Story Workshop provided an opportunity for the presenters to practice explaining their research without using scientific jargon. The presenters were asked to prepare a five- to ten-minute narrative of their research project that did not involve any visual aids. They were provided with guiding questions to help them structure these narratives, asking them to consider the broader importance, hypothesis, experimental design, and future directions of their research (Supplementary Material 1). Presenters were encouraged to keep their research story simple, without assuming pre-existing knowledge from the audience. They were invited to use familiar examples from everyday life to which the audience can relate and illustrate how beautiful and fascinating their work is. Their research story should highlight the relevance

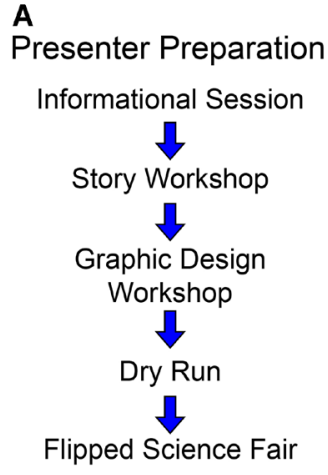

B

Figure 1. A) Scientists recruited to participate in the Flipped Science Fair first participated in an informational session to demonstrate interest and general communication skill. Researchers then completed a series of three workshops to prepare them for the oral and visual presentation of their research to middle school students. (B) The Flipped Science Fair event itinerary began with an orientation to help the student participants feel comfortable and confident to serve as judges. The schedule included time for both formal interactions during the poster judging and less formal interactions through activities and snacks/lunch.

and potential impact of their research. The participants were guided to address the following questions with their presentations: Why is this topic important? What question is the research trying to answer? What problem am I trying to solve? What is my hypothesis? What experiments and controls can I do to validate or reject the hypothesis? What conclusions can I draw form the results obtained? What is the next step in the research? Did I meet the goal? (see Supplementary Material 1 for further details).

During the workshop, the presenters were divided into small groups of four to five participants from diverse scientific backgrounds that included at least one Flipped Science Fair organizer. Local middle and high school teachers were also invited to attend the workshop to provide insight about the level of knowledge of the students who would be attending the event. The presenters shared their research story and received detailed feedback from group members about its clarity and cohesion, including suggestions for improvement when applicable. Group members acknowledged when they did not understand a word or concept, and helped the presenter adapt their research message until it was easier to grasp the concept. Through this process, the scientists listening in the group could experience the frustration that their audience might face and better understand how to appropriately tune the descriptive language to the audience while maintaining accuracy. It often took several revisions of the research story to strike the right balance of explaining scientific concepts without using too much jargon.

The Graphic Design Workshop allowed the presenters to obtain advice and feedback on the figures, graphs, and other visual aids on their poster. Prior to the workshop, the presenters were sent guidelines for preparing a poster presentation (Supplementary Material 2) as well as a sample poster 


\section{Can we use DNA to kill cancer cells?}

Melanie Reschke, Eric Song, Alex Piotrowski-Daspit, Mark Saltzman, Faye Rogers

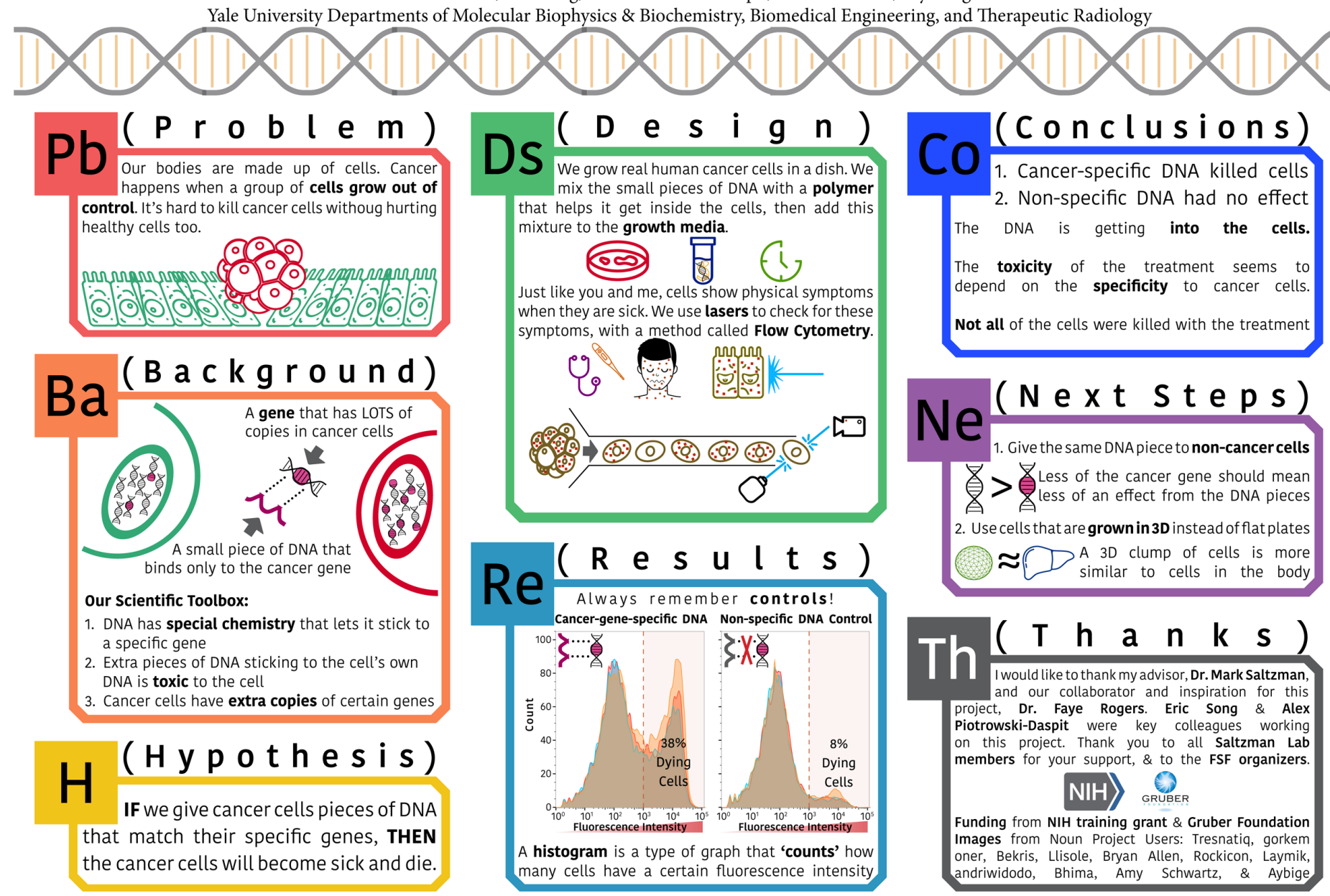

Figure 2. A representative poster presented by a researcher at the Flipped Science Fair.

template (Supplementary Material 3). The Graphic Design Workshop was hosted in a library computer lab equipped with Adobe Illustrator, and the presenters were stationed at computers while local graphic designers rotated around the room. The graphic designers helped the presenters refine the aesthetics of their poster drafts and suggested more accessible and intuitive ways to visually represent their scientific ideas and data (Figure 2).

Following the Research Story and the Graphic Design Workshops, the presenters were given several weeks to prepare their posters and refine their oral presentations. They then participated in a "Dry Run" to receive final feedback. The Dry Run was organized similarly to the Research Story Workshop; however, at this event the presenters used their posters to guide their research narrative. During each presentation, Flipped Science Fair organizers and other presenters provided critical feedback about all aspects of the presentation, such as the flow and clarity of the narrative and the effectiveness of the poster visuals and formatting. Additionally, the other group members asked scientific questions to mimic the environment on the day of the Flipped Science Fair event.

The Flipped Science Fair: The Event. The Flipped Science Fair was a half-day event hosted on a Saturday morning that had four main components: an orientation session, poster presentations, interactive science demonstrations, and an awards session (https://www.youtube.com/watch? $\mathrm{v}=\mathrm{rC} 3 \mathrm{~m}-$ Q8udJJU) (Figure 1B).

During the orientation session, Flipped Science Fair organizers introduced and explained the judging rubric to the middle school students (Figure 3 ). The rubric included nine questions separated into three sections - clarity, content, and presentation - to evaluate different aspects of the poster presentations. Responses were rated on a scale of one to five, with five being the best. To prepare the students for their role as judges, Flipped Science Fair organizers gave examples of what might be considered a "one" versus a "five" for each of the three categories. The rubric also included three qualitative questions asking the students to provide one thing they 


\section{FLIPPED SCIENCE FAIR EVALUATION SHEET}

\section{Please circle a value from 1 (lowest / not at all) to 5 (highest / completely) for each statement}

\begin{tabular}{|c|c|c|c|c|c|c|}
\hline \multirow{3}{*}{$\frac{\grave{E}}{\bar{\alpha}}$} & 1. The speaker explained their research without using confusing language & 1 & 2 & 3 & 4 & 5 \\
\hline & 2. The speaker explained why their research was important & 1 & 2 & 3 & 4 & 5 \\
\hline & $\begin{array}{l}\text { 3. The presenter explained how they developed their hypothesis / measures of } \\
\text { success }\end{array}$ & 1 & 2 & 3 & 4 & 5 \\
\hline \multirow{3}{*}{$\begin{array}{l}\text { 上 } \\
\mathbf{z} \\
\mathbf{z} \\
\mathbf{Z} \\
0\end{array}$} & $\begin{array}{l}\text { 4. Presentation was complete, including (a) background, (b) a hypothesis / } \\
\text { measures of success, (c) materials / methods, (d) key results, and (e) conclusions }\end{array}$ & 1 & 2 & 3 & 4 & 5 \\
\hline & 5. The presenter told a unified and complete story & 1 & 2 & 3 & 4 & 5 \\
\hline & 6. The presenter related everything back to their hypothesis / measures of success & 1 & 2 & 3 & 4 & 5 \\
\hline \multirow{3}{*}{ 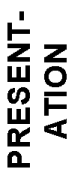 } & 7. The poster was clear / understandable without being overwhelming or confusing & 1 & 2 & 3 & 4 & 5 \\
\hline & 8. The speaker was confident and engaging throughout their presentation & 1 & 2 & 3 & 4 & 5 \\
\hline & 9. The speaker answered questions completely and without hesitation & 1 & 2 & 3 & 4 & 5 \\
\hline
\end{tabular}

Presenter's Name:

Display \#:

Judge's Name:

Stars:

Figure 3. Rubric used by middle school students to judge researcher poster presentations.

learned, one question they still had, and one piece of advice they would give for each presentation. The qualitative questions were not used in the evaluation of presenters for awards (see below), but were given to the presenters after the event so that they could have direct feedback on their strengths and weaknesses in communicating their science to a general audience.

After being trained as judges, the students were separated into groups of three to four and led to the poster presentations. The event included two one-hour long sessions; for each session the students visited three posters (Figure 4A). When the student groups arrived at one of the 33 posters, the

A

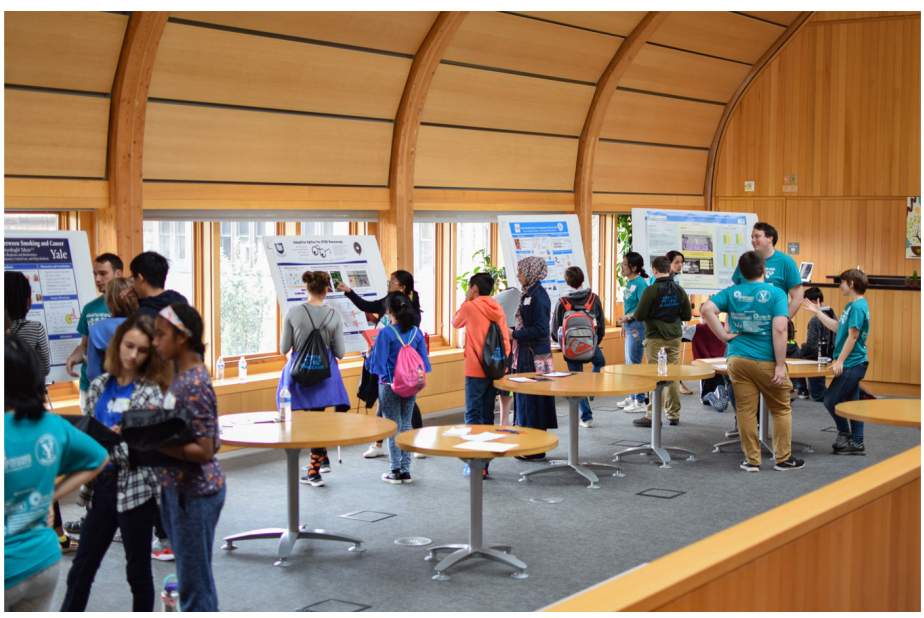

presenters briefly introduced themselves and explained how they became interested in science. This "introduction period" was an innovative aspect of the second Flipped Science Fair event that aimed to make the students more comfortable talking with and asking questions of the presenters. The poster presentations themselves were about fifteen minutes long, including time for questions from students. Students who asked particularly insightful questions (as determined by the presenters) were awarded star stickers, later used as a metric for rewarding the most engaged and thoughtful students. Finally, the students had a few minutes to complete the judging rubric before moving to the next poster. Volun-
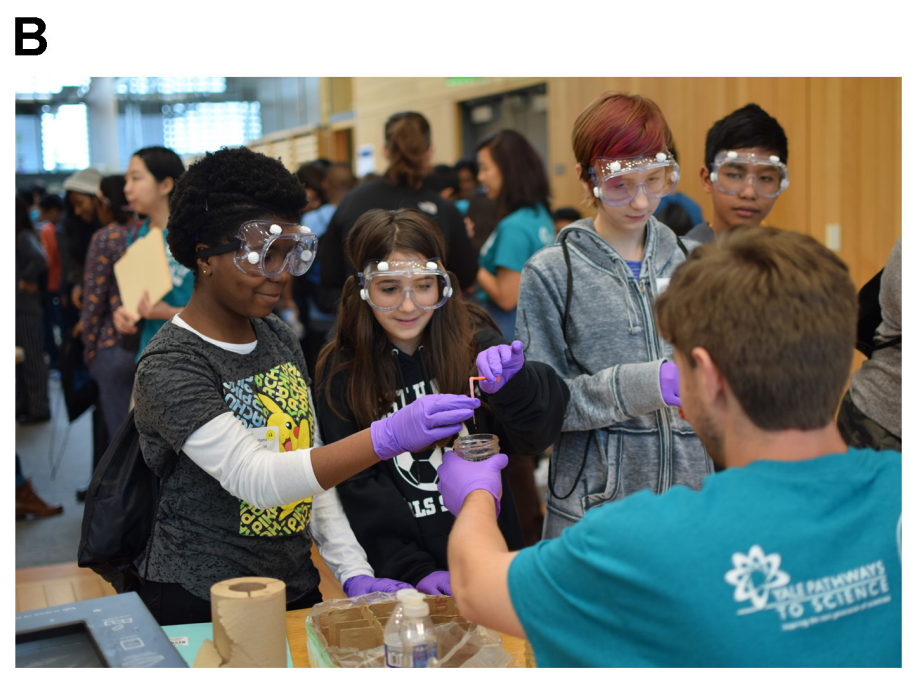

Figure 4. A) Group of middle school students interacting with a poster presenter and B) Middle School students involved in hands-on demonstrations. 
teers were stationed by the posters to facilitate timing and help students rotate between posters. Students that pre-registered via an online survey were able to indicate their scientific topic preferences but all students were exposed to a variety of research topics.

Between the two poster sessions, there was a fifty-minute "break" period where the students could participate in interactive science demonstrations. A variety of science outreach groups at Yale provided the demonstrations, which included extracting DNA from strawberries, controlling a robotic claw, and handling dinosaur fossils (Figure 4B). These hands-on activities exposed the students to additional fields of scientific research not represented by posters, and gave the students the opportunity to act as scientists, making hypotheses about what they might observe from the demonstration.

The conclusion of the Flipped Science Fair was an awards session that reported the results of the science fair judging. Throughout the day, volunteers collected the judging rubrics from the students and tallied the responses in each category for every presenter. The presenter with the highest overall score, as well as those with the highest score in each category (clarity, content, and presentation), were awarded with a small prize and gave an abbreviated research presentation to the entire audience. At the end of the awards session, prizes were also given to the students who received the most star stickers for asking thoughtful questions.

Assessment. To assess the usefulness of the Flipped Science Fair for participants, we surveyed presenters and middle school students. Questions for the students evaluated their learning experience at the event, while questions for the presenters focused on their professional development in science communication. Student surveys collected self-reported demographic data, which allowed us to evaluate the diversity of our student group. The results of the questionnaires, administered as a printed sheet to middle school students and as online surveys to presenters, are discussed in more detail below.

\section{RESULTS AND DISCUSSION}

Participant Students: Our Judges. Prior to the event, 169 students (or their parents) pre-registered for the Flipped Science Fair through an online survey link included on promotional materials. Pathways to Science leveraged their extensive communication network to promote the event and orchestrated the registration process. Students were recruited by a combination of emails, postcards, and giving flyers to local middle schools. Of the pre-registered students, 123 participated in the event ( $73 \%$ attendance) and 117 of them completed the post-event survey (95\% response rate). 78 of the 123 attendees were students in the Pathways to Science program. Self-identified student demographics are reported in Figure 5A-B. Since students were able to check as many boxes as applicable for racial/ethnic demographics, the 24 students that selected more than one, were collapsed into the most underrepresented group to allow for more straightforward analysis. $42 \%$ of students indicated they were from at least one historically underrepresented background. There was a roughly even split between male and female students (Figure 5B). Interestingly, 29\% of the students participating in the event had never attended a science-related activity outside their school before the Flipped Science Fair (data not shown).

Impact on Students. One of the primary goals of the Flipped Science Fair was to expose local middle-school students to an array of scientific fields and challenge them to think critically about scientific research. We surveyed the students to learn about the success of this aim (Figure 6A). Feedback from students was overwhelmingly positive, with $96 \%$ either agreeing or strongly agreeing that they enjoyed the event overall. The majority of them also stated that, after the event, they are more interested in science than before. Areas for improvement identified from student feedback are the level of preparedness felt by students (only $72 \%$ responded positively) and level of comfort talking to presenters ( $85 \%$ positive responses). As a result of this feedback, future Flipped Science Fairs will include a more effective training session at the beginning of the event to ensure that the students understand the judging rubric and their role in evaluating the poster presentations. Despite $96 \%$ of students overall enjoying the event, only $81 \%$ of students responded affirmatively that they would recommend the event to a friend (14\% remaining neutral) which may be another area for improvement.

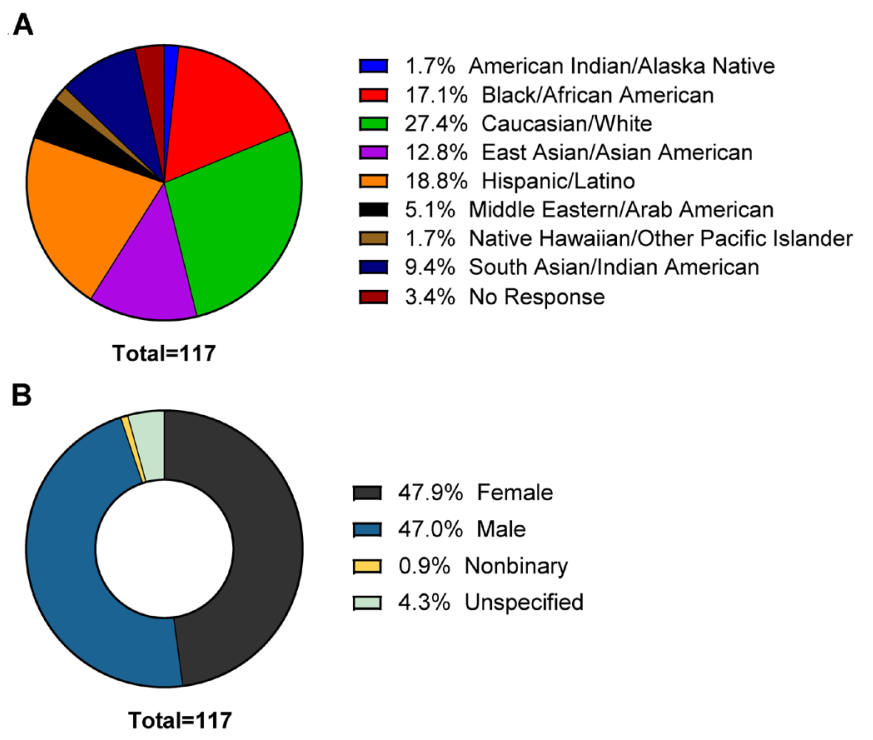

Figure 5. Student participants' demographics. 


\section{Student Feedback}

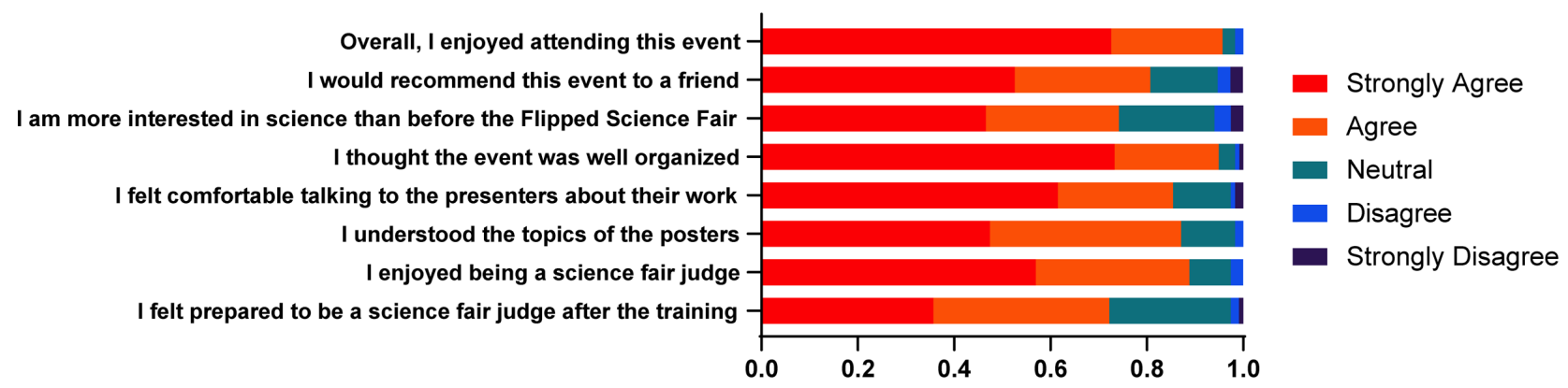

B

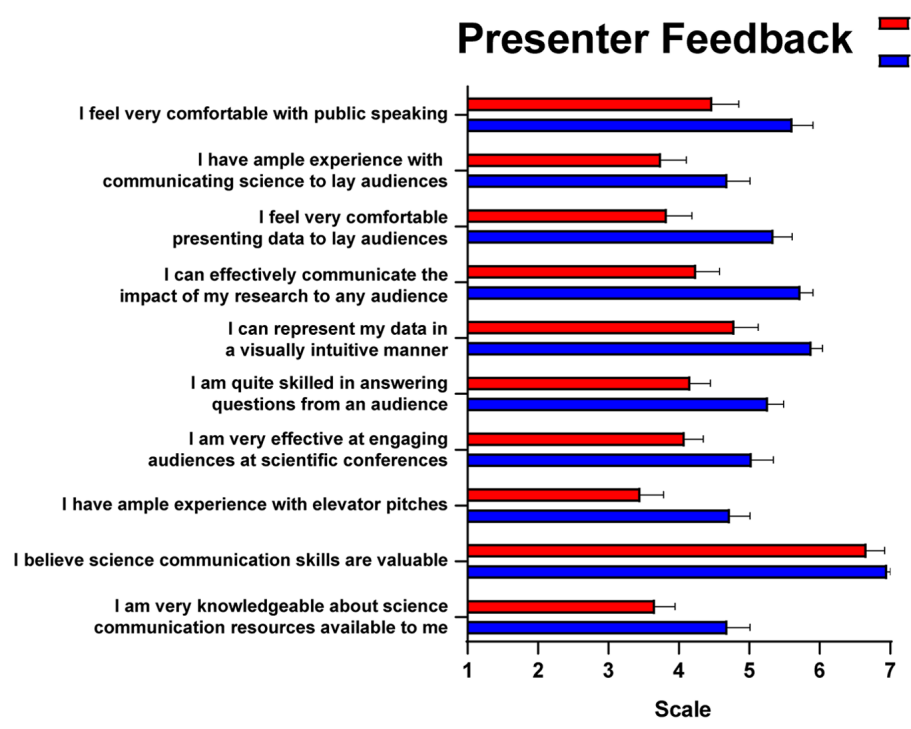

C

\begin{tabular}{|c|c|c|}
\hline Pre & Post & Improvement \\
\hline 4.5 & 5.6 & 1.1 \\
\hline 3.8 & 4.7 & 0.9 \\
\hline 3.8 & 5.3 & 1.5 \\
\hline 4.3 & 5.7 & 1.5 \\
\hline 4.8 & 5.9 & 1.1 \\
\hline 4.2 & 5.3 & 1.1 \\
\hline 4.1 & 5.0 & 1.0 \\
\hline 3.5 & 4.7 & 1.3 \\
\hline 6.7 & 7.0 & 0.3 \\
\hline 3.7 & 4.7 & 1.0 \\
\hline
\end{tabular}

Figure 6. Results of students and presenters event evaluation feedback.

Impact on Presenters. The Flipped Science Fair provided an opportunity for early career researchers at Yale to develop their skills at communicating science to a general audience. As detailed above, the presenters participated in workshops and received training materials to help them prepare posters to share their research with local middle school students. The majority of presenters believed that the number of workshops was appropriate to prepare them for the event; many cited the Dry Run as particularly beneficial for the ability to practice their presentation in front of an audience of non-experts. Similarly, many presenters stated that their favorite aspect of the Flipped Science Fair event was their interactions with the engaged, thoughtful middle school students during the poster presentations. For these reasons, 11 of the 27 presenters that participated in the first Flipped Science Fair, returned as presenters the following year. While presenters' responses to the workshops and event were largely positive, we also received valuable feedback about ways the Flipped Science Fair could be improved in the future. For example, the informational session was initially termed an audition, however this terminology was deemed intimidating by the participants and a limiting factor for their recruitment. We also condensed the interval between workshops to decrease overall preparation time commitment and reduce the number of poster presentations during the event.

We performed a more quantitative evaluation of the training materials and workshops by surveying the presenters' attitudes towards science communication and level of comfort in explaining their research to others before and after the event (Figure 6B). We received 24 responses for the pre-survey and 26 responses for the post-survey (returning presenters also completed the post-survey). Each survey question was scored on a scale of 1 (strongly disagree) to 7 (strongly agree). The data were analyzed based on average differences in score from surveys collected before and after the event (Figure 6C). Questions related to communicating with a general audience and learning about resources for effective science communication showed the largest positive difference in score, indicating the greatest improvement. Overall, the results showed that the Flipped Science Fair achieved 
its goal of increasing the presenters' ability to comfortably and effectively present their research to the general public (Bass, 2016; Bernard and Michaut, 2013; Brownell et al., 2013; Leshner, 2003; Moni et al., 2007; Oliveira et al., 2019; Petzold and Dunbar, 2018; Ufnar et al., 2012).

\section{CONCLUSIONS}

Here, we have presented a model for a Flipped Science Fair in which middle school students judge poster presentations given by early stage researchers in a variety of scientific disciplines. The Flipped Science Fair gave the middle school students the opportunity to critically evaluate diverse scientific research and trained the researchers to present their research clearly and engagingly to a non-expert audience. Surveying both groups of participants indicated that these aims were successful; responses to the event were overwhelmingly positive. In particular, the middle schoolers reported a strong understanding of the research being presented, and the presenters noted that the Flipped Science Fair training increased their comfort in explaining their research to a lay audience.

To evaluate the long-term impact of the Flipped Science Fair and other extracurricular STEM programming, the Yale Pathways to Science program maintains an extensive, longitudinal database of their students that tracks their academic status through college. The database includes information about the students' demographics, which outreach programs they attend, their academic records, and their college attendance and major. With only two years of Flipped Science Fair data, no conclusions can be made regarding the event's impact on student trajectories. However, we note that analysis of such data in general could enable outreach organizers to identify which type of programming best engages and inspires students to pursue careers in STEM. Given the diverse demographics of the student population in Greater New Haven and the Flipped Science Fair's percentage of underrepresented minorities was around $40 \%$, the data could be especially useful for identifying successful STEM programming for underrepresented students in these fields. It is important to mention that the Flipped Science Fair's proportion of African American students was just over half the proportion of African American New Haven residents. Our marketing was initially limited to Pathways to Science and New Haven Public School students, but we expanded our advertising two weeks prior to the registration deadline to ensure we hosted as many students as we had the ability to. Enriching for underrepresented students is a major focus for future Flipped Science Fairs.

In order to expand the reach of our public engagement efforts, we have begun partnering with local community leaders to host several smaller, satellite Flipped Science Fair events. These events have included poster presentations at local libraries, community meetings, schools, summer camps, and neighborhood festivals. Satellite events have proven to be an effective way to repurpose posters and to give presenters more opportunities to explain their research to a wider audience, but on a smaller scale. These satellite events also stand to engage students that may not already be interested in STEM, since we are meeting families in their communities as opposed to a separate STEM-focused event. Due to the COVID-19 pandemic, we were unable to host the third iteration of the Flipped Science Fair. We have transitioned several of our poster presentations to an online format and have been able to reach many new local students. We plan to continue and expand these complementary efforts to ensure we maximize the return on the substantial amount of preparation required to create an engaging and understandable presentation of science to a broad audience.

\section{ASSOCIATED CONTENT}

Supplemental material mentioned in this manuscript can be found uploaded to the same webpage as this the manuscript.

\section{AUTHOR INFORMATION \\ Corresponding Authors}

Lorena Benedetti, PhD. 19700 Helix Drive, Ashburn, VA 20147. (571) 209-4000x3296. benedettil@janelia.hhmi.org

Richard Crouse. 301 Cedar Street, New Haven, CT 06519. (203) 737-2042.richard.crouse@yale.edu

\section{Author Contributions}

L.B and R.B.C. contributed to the organization of the event, training of the presenters, fundraising, and manuscript writing. Both authors approved the final version of the manuscript.

\section{ACKNOWLEDGMENTS}

We would like to thank all the organizers, poster presenters, and volunteers that made this event possible. The support of the American Society for Cell Biology and in particular Erika Shugart, Thea Clark, Dolly Hayed, Rebecca Nall. Claudia Merson and Maria Parente from Pathways to Science, Carol Russo and Jennifer Franzoni. We would like to thank Carolyn Ott and Sheryl Daigle Switaj for critically reading the manuscript.

\section{FUNDING SOURCES}

The Flipped Science Fair was generously supported by the following grants, organizations, and departments: Amer- 
ican Society for Cell Biology Public Engagement Grant, Yale School of Medicine Department of Neuroscience, Yale School of Medicine Department of Genetics and Genomics of Human Disease Training Grant (NIH 5T32HD007149-40), Yale Raymond and Beverly Sackler Institute for Biological, Physical and Engineering Science, Cancer Systems Biology at Yale (NCI U54CA209992), United Health Care (Gordon Stiglbauer), Yale School of Medicine Department of Psychiatry, Kleo Pharmaceuticals, Yale School of Medicine Department of Physiology, Yale School of Medicine Department of Pharmacology, Yale School of Medicine Interdepartmental Neuroscience Program, Bell Power Systems LLC, Yale Molecular Biophysics and Biochemistry, Yale Office of Career Strategy, Yale School of Medicine Department of Immunobiology.

\section{ABBREVIATIONS}

FSF: Flipped Science Fair; LB: Lorena Benedetti; RBC: Richard B. Crouse; YSD: Yale Science Diplomats

\section{REFERENCES}

Alberts, B. (1994). Scientists have important roles, responsibilities in future of science education. Forum on Education newsletter, November. www.aps.org/units/fed/newsletters/ nov94/alberts.html.

Bass, E. (2016). The importance of bringing science and medicine to lay audiences. Circulation, 133, 2334-2337. doi:10.1161/circulationaha.116.023297

Benedetti, L., and Crouse, R. (2018). Flipped science fair. Molecular Biology of the Cell, 29 (26), 5-5.

Bernard, V., and Michaut, M. (2013). Explain bioinformatics to your grandmother! PLOS Computational Biology, 9, e1003305. doi:10.1371/journal.pcbi.1003305

Brownell, S.E., Price, J.V., and Steinman, L. (2013). Science communication to the general public: Why we need to teach undergraduate and graduate students this skill as part of their formal scientific training. Journal of Undergraduate Neuroscience Education, 12, E6-E10.

Colwell, R. (1998). Address to the DC Science Writers Association. National Science Foundation, Office of Legislative and Public Affairs. www.nsf.gov/news/speeches/colwell/ rc80908.htm.

DeClue, M.E., Johnson, K., Hendrickson, H., Keck, P. (2000). Stimulate high school science Fair participation by connecting with a nearby college. Journal of Chemical Education, 77, 608. doi:10.1021/ed077p608

Fink, R.D. (2009). It's elementary: Science buddies bring biology to life. PLOS Biology, 7, e1000182. doi:10.1371/journal. pbio. 1000182
Fouad, N.A., and Santana, M.C. (2017). SCCT and underrepresented populations in STEM fields: Moving the needle. Journal of Career Assessments, 25(1), 24-39. doi: $10.1177 / 1069072716658324$

Friedman, D.P. (2008). Public outreach: A scientific imperative. Journal of Neuroscience, 28, 11743-11745. doi:10.1523/ jneurosci.0005-08.2008

Gamse, B., Smith, W.C., Parsad, A., Dreier, J., Neishi, K., Carney, J., Caswell, L., Breaux, E., McCall, T., and Spader, J. (2010). Evaluation of the National Science Foundation's GK-12 program. Cambridge, MA: Abt Associates.

Holmes, N., and Berube, A. (2014). City and metropolitan inequality on the rise, driven by declined incomes. Brookings. https://www.brookings.edu/research/city-and-metropolitan-inequality-on-the-rise-driven-by-declining-incomes/

Johnson, A., and Okoro, M. (2016). How to recruit and retain underrepresented minorities. American Scientist, 104, 76. doi:10.1511/2016.119.76

Kolko, J. (2016). "Normal America" is not a small town of white people. FiveThirtyEight. https://fivethirtyeight.com/features/normal-america-is-not-a-small-town-of-white-people/

Lacalle, S., and Petruso A. (2012). The value of partnerships in science education: a win-win situation. Journal of Undergrad Neuroscience Education, 11, A97-A105.

Landivar, L.C. (2013). Disparities in STEM employment by sex, race, and Hispanic origin. Washington DC: US Census Bureau.

Leshner, A.I. (2003). Public engagement with science. Science, 299, 977-977. doi:10.1126/science.299.5609.977

Mernoff, B., Aldous, A.R., Wasio, N.A., Kritzer, J.A., Sykes, E.C.H., and O'Hagan, K. (2017). A reverse science fair that connects high school students with university researchers. Journal of Chemical Education, 94, 171-176. doi:10.1021/acs.jchemed.6b00111

Mervis, J. (2010). Let's have the kids judge. Science, 329, 270 270. doi:10.1126/science.329.5989.270-e

Moni, R.W., Hryciw, D.H., Poronnik, P., and Moni, K.B. (2007). Using explicit teaching to improve how bioscience students write to the lay public. Advances in Physiology Education, 31, 167-175. doi:10.1152/advan.00111.2006

Oliveira, L.M.A., Bonatelli, M.L., and Pinto, T.C.A. (2019). DivulgaMicro: A Brazilian initiative to empower early-career scientists with science communication skills. Journal of Microbiology and Biology Education, 20. doi:10.1128/ jmbe.v20i1.1616

Petzold, A.M., and Dunbar, R.L. (2018). The art of talking about science: beginning to teach physiology students how to communicate with nonscientists. Advances in Physiology Education, 42, 225-231. doi:10.1152/advan.00053.2017 
Thompson, S., Collins, A., Metzgar, V., Joesten, M., and Shepherd, V. (2002). Exploring graduate-level scientists' participation in a sustained $\mathrm{K}-12$ teaching collaboration. School Science and Math, 102, 254-265.

Ufnar, J.A., Kuner, S., and Shepherd, V.L. (2012). Moving beyond GK-12. CBE-Life Science Education, 11, 239-247. doi:10.1187/cbe.11-12-0119 